\title{
Apresentação
}

\section{Dossiê As fronteiras do trabalho em tempos de crise}

\author{
Katiuscia Moreno Galhera ${ }^{1}$ \\ Ricardo Framil Filho ${ }^{2}$ \\ Leonardo Antonio Silvano Ferreira ${ }^{3}$
}

Com grande satisfação, apresentamos o dossiê Fronteiras do Trabalho em Tempos de Crise, fruto de intenso trabalho que mobilizou dezenas de pesquisadores interessados pelo tema nos últimos meses. Desde a elaboração da chamada até a finalização deste número, foram diversos e frutíferos os debates conceituais, metodológicos e práticos, o que envolveu, entre o corpo editorial da revista MovimentAção, a equipe do Programa de Pós-Graduação em Sociologia da Universidade Federal da Grande Dourados (PPGS-UFGD), editores convidados, pareceristas, autores e parceiros, um número expressivo de especialistas de diferentes áreas, países e universidades. O número de submissóes superou as nossas expectativas mais otimistas, o que exigiu um grande esforço para que o dossiê esteja à altura da proposta da revista, combinando a excelência acadêmica com uma postura aberta e convidativa.

Todos os artigos recebidos, desde que tenham cumprido os critérios mínimos exigidos pela chamada, foram encaminhados à avaliação por pares anônima, no que evitamos ao máximo a imposição de filtros editoriais prévios. Essa forma de trabalhar não está isenta de desafios e exigiu a mobilização de mais de 40 pareceristas, mas nos pareceu ser a melhor maneira de tratar as muitas submissóes recebidas. O resultado é um dossiê abrangente e que apresenta contribuiçôesde autores(as) em diferentes etapas da carreira, de recém-graduados(as) a doutores estabelecidos em importantes universidades e instituiçóes de pesquisa.

Agradecemos enormemente a todas as pessoas envolvidas nessa construçáo coletiva. Diante da drástica redução do investimento em ciência e nas universidades públicas, além da degradação das proteçôes sociais e das condiçôes de vida em geral, a abnegação dos que se dispuseram a colaborar com a produção deste dossiê é inspiradora e demonstra a vitalidade dos estudos do trabalho hoje. Por outro lado, não poderíamos ignorar que, com poucas exceções, esses esforços foram voluntários e, quando obtiveram algum apoio externo, como no caso das poucas bolsas que ainda existem

\footnotetext{
1 Professora visitante no Programa de Pós-Graduação em Sociologia (UFGD). Doutora em Ciência Política (UNICAMP) com visiting scholar period em direitos globais de trabalhadores(as) na Penn StateUniversity (PSU) e estágio pós-doutoral em Sociologia (UEL). E-mail: katiuscia.mg1@gmail.com

2 Doutorando no Programa de Pós-Graduação em Sociologia da Universidade de São Paulo. E-mail: framilfilho@gmail. com

3 Mestre em Ciências Sociais pela Universidade Estadual de Londrina (2014). Discente do Programa de Pós-Graduação em Ciências Sociais pela Faculdade de Filosofia e Ciências da Universidade Estadual Paulista "Júlio de Mesquita Filho", Campus de Marília. Docente do sistema de Ensino à Distância-EAD na Universidade Pitágoras Unopar, e Universidade Uniderp - Anhanguera. Professor de Sociologia da educação básica na Secretaria da Educação e do Esporte do Estado do Paraná. E-mail: leonardosilvanoferreira@gmail.com
} 
no país, mal remunerados. O trabalho em pesquisa e a carreira no magistério requerem horas de trabalho náo pago que poderiam ser destinadas ao lazer, cuidado com quem se ama, organizaçáo de base e educação popular. Seria ingenuidade, além disso, acreditar que o número de submissóes reflete apenas o interesse despertado pelo tema. Há também a pressão pelo produtivismo acadêmico e a corrida por publicaçóes, frequentemente incentivadas por programas de pós-graduaçáo, agências de fomento e o próprio Ministério da Educação. Esperamos, pelo menos, que os debates aqui suscitados contribuam com a elucidação da perversidade desse tipo de lógica.

Da perspectiva proposta pelo dossiê, é relevante que as últimas décadas tenha feito com que seja menos controverso, em comparaçáo ao período anterior, a associação entre as ideias de capitalismo e crise social. Não obstante, o reaparecimento da preocupação com o capitalismo não foi imediatamente acompanhado por um resgate da centralidade da categoria trabalho na teoria social. Pelo contrário, em abordagens influentes e variadas, não foi descartada, de forma implícita ou explícita, a conclusão central acerca do "fim da sociedade do trabalho", ideia cuja popularidade foi crescente desde meados do século passado. Ainda que em posição relativamente marginal, é claro, os estudos críticos do trabalho nunca interromperam seu desenvolvimento, mas tendências recente sparecem indicar uma revitalização mais geral do campo.

O chamado "precariado"; a "uberização" e as plataformas digitais; os dilemas sanitários, econômicos e sociais intensificados pela pandemia, inclusive em suas dimensôes racial, étnica, de gênero e tantas outras; episódios notáveis de protesto e luta social com base econômica (ou, o que é mais preciso, de classe) em diferentes partes do mundo - todos esses elementos têm colocado a experiência contemporânea do trabalho e o conflito capital-trabalho na pauta dia. Essa urgência e diversidade estão representadas nas páginas que se seguem.

$\mathrm{Na}$ primeira parte do dossiê, elencamos pesquisas que tratam principalmente de aspectos da exploração e, na segunda parte, da agência de trabalhadores(as) e outros atores frente ao avanço do capital. Abrimos a primeira seção com a reflexão de Agnes Souza sobre "Uberização, Ode à Crise e Precarização", para então focar em dois novos artigos que tratam do tema: "O Perfil do Motorista de Aplicativo no Brasil", de Ana Bessa, e "Game Over: a Gestão Gamificada do Trabalho", de Viviane Vidigal. Hannah Nario-Lopez aborda a gestão das emoções em "Emotion Management among Officers in a Philippine City Jail" e antecede a contribuição de José Neves, que aborda alienação em "Implicações Ontológicas das Redes Sociais". Em seguida, João Russo e Vinicius Souza trazem "A Terceirização na UFGD em tempos de Pandemia do Sars-Cov-2". Cesar Sanson retoma o tema da centralidade do trabalho em "O Trabalho em Tempos de Crise" e Julia Scavitti, o trabalho migrante em "E essa tal Liberdade? Paradoxos de Imigração e Trabalho". João Parra conclui a seção com "The Great Reset", sobre a contemporaneidade da exploraçáo em startups.

A segunda seção se inicia com a agência de trabalhadores em "Narrativas em Rede: o Breque dos apps e as Novas Formas de Manifestação de Trabalhadores em Plataformas Digitais", de Nina Desgranges e Wickson Ribeiro. Em seguida, Mariana Afonso aborda as "Respostas de Movimentos Sociais Feministas à Pandemia de Covid-19" e Alexandre Ramos trata de trabalhadores da saúde (e outros grupos) em "Desafiando as Fronteiras Entre Sindicatos e Movimentos Sociais em Meio à Pandemia: Campanhas de Coalizão em Defesa do SUS na cidade de São Paulo, em 2020”. O artigo de Guilherme Nicolau, Ivan Pereira e Claudia Guebel conclui com um estudo comparativo sobre o direito à cidade em "Conurbano e Participação Popular no Século XXI".

Por fim, apresentamos em tradução para o português contribuição de Marcel Van der Linden, historiador cuja obra é fundamental para o debate em vista. No artigo, publicado originalmente na Global Labour Journal, revista de referência para estudiosos do trabalho, o autor apresenta um 
balanço das formas tradicionais de organizaçáo trabalhista e aponta para a necessidade de um novo processo de "demarcação das classes trabalhadores", redesenhando as fronteiras que separam as diferentes categorias de trabalhadores, sugerindo uma conceitualização expandida do trabalho e dos trabalhadores.

Boa leitura! 